\title{
Fund Matching between Fund-Raisers and Investors in Financing Platform with Consideration of Default Risk
}

\author{
Kenan Li, ${ }^{1}$ Xin Li ${ }^{1},{ }^{1}$ Zhijun Lin, ${ }^{1}$ Jing Lu, ${ }^{2}$ and Pak Hou Che ${ }^{1}$ \\ ${ }^{1}$ School of Business, Macau University of Science and Technology, Macau SAR, China \\ ${ }^{2}$ YGSoft Incorporation, Zhuhai, China \\ Correspondence should be addressed to Xin Li; xli@must.edu.mo
}

Received 28 October 2021; Accepted 8 December 2021; Published 27 December 2021

Academic Editor: Xinsheng Xu

Copyright (c) 2021 Kenan Li et al. This is an open access article distributed under the Creative Commons Attribution License, which permits unrestricted use, distribution, and reproduction in any medium, provided the original work is properly cited.

We construct a stochastic model to study the fund matching between fund-raisers and investors in a financing platform. The raising time is assumed to be a random variable. Then, there is a successful transaction probability that the fund matching is realized. Meanwhile, the interest and the commission rate that the platform earns affect the value of the probability. The platform maximizes its revenue by adjusting the commission rate. We find that the optimal commission rate decreases in investment time. However, when the time interval between two adjacent investments obeys the general distribution, the optimal commission rate increases in the annual interest rate. Besides, we extend the model into a duopoly case in which two fund-raisers compete for customers in the same platform by deciding their own interest rate. Due to lacking competition, the optimal interest rate in the monopoly case is lower than that in the duopoly case. Because the interest rate is the cost for the fund-raiser, the expected profit of the fund-raiser in the monopoly is higher than the expected profit of each fund-raiser in the duopoly case but lower than the total expected profit of two fund-raisers. The platform should choose some small loans as far as possible. The loans with smaller amount are easier for the platform to complete fundraising. For those large loans, the platform should try to ask for higher interest rates or more sufficient time to raise funds.

\section{Introduction}

With the world entering the information age and the rapid development of the Internet, Internet finance has gradually received people's attention. Especially in recent years, Internet finance represented by third-party payment is unprecedented prosperity in China. In this context, peer-to-peer(P2P) network loan in Internet finance has also developed rapidly in recent years and has become an important part of public investment and financial management. In its development, China has become the market with the most P2P lending platforms [1].

Behind the rapid development of online financing platforms, there are very big hidden dangers. The general public do not see the risks behind the online financing platform. Due to the lack of regulatory measures, the P2P loan may not come back and some P2P online lending platforms may lead to bankruptcy.
Compared with the traditional credit industry, the online financing platform is carried out through the Internet, so the information asymmetry is more serious. It is difficult for the P2P online lending platform and the borrower to understand the details of the lender, and the borrower also cannot understand the details of the platform. There are many problems, such as the mismatch of time and funds between fund-raisers and investors. The problem of time and fund mismatch between fund-raisers and investors refers to that when a fundraiser applies for a loan, it may need more than one investor. There is a time difference between them. When the time difference is longer than the required raising time, the loan will be invalid. However, if the required raising time is too long, the fund will be idle, resulting in unnecessary waste. Because a lower commission rate increases the investor's willingness to invest, thereby increasing the probability of a successful match, but decreases the income of the platform. Therefore, how to decide the commission rate for the platform is very important. 
The following are our main contributions to the literature:

(1) We construct a stochastic model to study the fund matching between fund-raisers and investors in a financing platform. The raising time is assumed to be a random variable. Then, there is a successful transaction probability that the fund matching is realized. Meanwhile, the interest and the commission rates that the platform earns affect the value of the probability. The platform maximizes its revenue by adjusting the commission rate.

(2) When the raising time is uniformly distributed, we find that the optimal commission rate increases in the probability of borrower default but decreases in the annual interest rate and the loan duration. We extend the model into a more general one, in which the platform needs more than one investor to raise enough money for the borrower, and the time interval between two adjacent investments obeys the general distribution. We find that the optimal commission rate increases in the annual interest rate and raising time but decreases in the loan duration.

(3) Besides, we extend the model into a duopoly case in which two fund-raisers compete for customers in the same platform by deciding their own interest rate. Due to lacking competition, the optimal interest rate in the monopoly case is lower than that in the duopoly case. Because the interest rate is the cost for the fund-raiser, the expected profit of the fund-raiser in the monopoly is higher than the expected profit of each fund-raiser in the duopoly case but is lower than the total expected profit of two fund-raisers.

The rest of this paper is organized as follows: In section 2, we review the related literature. In section 3, we establish the basic model and extend the model to a general monopoly case. In section 4 , we present sensitivity analysis. In section 5 , we extend the model into a competition case. We conclude the paper in Section 6. The proofs are relegated to the appendix.

\section{Literature Review}

In 2005, the first online P2P platform appeared in the United Kingdom, and online P2P platforms soon spread to the United States, as represented by Prosper.com and the Lending Club [2]. In 2013, Alibaba launched Yu Ebao, an Internet banking site, which achieved great success and greatly stimulated online finance. Soon, China's P2P finance began to develop rapidly [3].

The P2P platform can be divided into two types: pure intermediary and compound intermediary according to different operation modes. Pure intermediary means that the platform only acts as an intermediary between investors and borrowers, providing a platform for both sides of the loan without participating in the loan process and charging the corresponding service fees. Compound intermediary means that the platform not only provides intermediary services but also participates in the lending process to guarantee the lending [4].

Foreign scholars believe that the credit risk on the P2P platform mainly comes from two aspects: information asymmetry and lack of guarantee [4]. In order to obtain the loan, the borrower will inevitably provide false information, at least conceal the unfavorable information to himself, which causes the investor to invest the loan to the borrower with high risk. This is a phenomenon of adverse selection [5]. P2P loan objects are mainly individuals, and the general platform does not require borrowers to provide a guarantee, so the risk of lending increases [6].

After the introduction of the P2P loan into China, its business model has changed to adapt to the inherent Chinese traditional concept of financial institutions. China's P2P platform is forced to play the role of information intermediary and credit intermediary, which is considered to transfer the credit risk of borrowers to the P2P platform [7]. In China, some domestic scholars study the risk of P2P lending from the perspective of credit risk. More domestic literature reveals the risks of $\mathrm{P} 2 \mathrm{P}$ from the perspective of law and regulation [4]. It is also confirmed that if the P2P platform does not have good internal operating procedures (for example, the borrower's credit review), the borrower's credit risk may be transferred to the P2P platform [8]. Some scholars propose a new method to construct the credit risk assessment model of the P2P lending market by extracting text features [9].

Managers of small and medium-sized enterprises can meet the liquidity needs of their companies by using P2P lending financial technology companies [10]. P2P investors will invest more money in the loans of borrowers they are familiar with. Subsequently, more initial investment from the investors familiar with the borrowers will be related to the higher possibility of obtaining a second loan from the P2P lenders, the larger investment from other P2P investors, and the lower postdefault risk [11]. The lower the loan interest rate, the longer the loan term and the higher the popularity of the platform, the healthier it is. We also conclude that platforms with public ownership may have greater financial stability [12].

\section{Platform Model}

3.1. Basic Model. We consider a financing platform in a transaction. We assume that the platform issues a loan with a total amount of $d$ at time 0 , with the required raising time $t$. If the financing is not completed within $t$, the scheme will be cancelled, and the funds already raised will be returned to the investors. $r$ is denoted as the annual interest rate of the loan. The interest starts to accrue after time $t$, and the loan duration is denoted as $l$. The loan will mature and settle with the principal and interest payment at time $t+l$. If the loan matures, the platform will collect the commission from the successful transaction. Usually, the commission rate is a fixed proportion of the interest $\alpha$, and the value range is between 0 and 1 . If the borrower defaults, the platform will compensate the investors for the principal. The probability of default is denoted as $p_{d}$. The platform is an intermediary 
and guarantor and collects a commission from a successful transaction.

The real raising time is a random variable, denoted as $X$, which is distributed in a uniform distribution with the expectation of $\mu$. Assume $\mu$ is related with $r$ and $\alpha$, that is, $\mu=1 / \operatorname{ar}(1-\alpha)$, where $a$ is a sensitivity factor of the investors' net annual interest. Then, the probability of a successful transaction is $\operatorname{Prob}\{X<t\}=p$, and we obtain the following formula:

$$
p=\int_{0}^{t} \frac{\operatorname{ar}(1-\alpha)}{2} \mathrm{~d} x=\frac{\operatorname{ar}(1-\alpha) t}{2} .
$$

The expected income of the financing platform in a transaction can be expressed as follows:

$$
\pi=\alpha \operatorname{drlp}\left(1-p_{d}\right)-(d+(1-\alpha) \operatorname{drl}) \mathrm{pp}_{d}=\alpha \operatorname{drlp}-(d+\operatorname{drl}) \mathrm{pp}_{d}
$$

where $\alpha \operatorname{drlp}\left(1-p_{d}\right)$ is the expected commission revenue of the financing platform from a transaction, and $(d+(1-$ $\alpha) \mathrm{drl}) \mathrm{pp}_{d}$ is the expected default cost from a transaction.

The platform maximizes its revenue by adjusting the commission rate $\alpha$. Then, we obtain the following proposition:

Proposition 1. The optimal commission rate is

$$
\alpha^{*}=\frac{r l+p_{d}+2 r l p_{d}}{2 r l\left(1+p_{d}\right)}=\frac{1}{2}+\frac{1 / r l+1}{2\left(1 / p_{d}+1\right)} .
$$

Clearly, the optimal commission rate $\alpha^{*}$ increases in the probability of borrower default $p_{d}$ but decreases in the annual interest rate $r$ and the loan duration $l$. If the probability of borrower default $p_{d}$ increases, the risk of the platform and the expected default cost will be higher such that the platform needs to increase the commission rate to compensate for the high risk. If the annual interest rate $r$ or the loan duration $l$ increases, the revenue of the successful transaction will be increased, so in order to obtain the high revenue, the platform will increase the probability of a successful transaction by decreasing the commission.

Next, we expand the model into a more general case, and we obtain a similar result.

3.2. Extend Model. In reality, one investor may be not enough for the borrower. The platform needs more than one investor to raise enough money for the borrower, so we will construct a more realistic model to investigate the money matching.

We assume that a borrower needs $n$ investors, and the investment of each investor is independently and identically distributed. The time interval between two adjacent investments is $x_{i}, i=1,2 \ldots n$, obeying the general distribution with expectation $\mu$ and standard deviation $\sigma$. Assuming that $\mu$ is related with $r$ and $\alpha$, such that

$$
\mu=\frac{1}{\operatorname{br}(1-\alpha)}
$$

where $b$ is a sensitivity factor of the investors' net annual interest. According to the above setting, the total raising time is denoted as $Y=\sum_{i=1}^{n} x_{i}$. Since the loan raising time is $t$, the probability of the loan raising is $\operatorname{Prob}\{Y \leq t\}$. Since $x_{i}$ has a general distribution, and they are independent of each other, so the sum must be normally distributed, and the expected expectation is $n \mu$, and the standard deviation is $\sqrt{n} \sigma$. Then, the expression of $\operatorname{Prob}\{Y \leq t\}$ is as follows:

$$
\operatorname{Prob}\{Y \leq t\}=p(\alpha)=\frac{1}{\sqrt{2 \pi n} \sigma} \int_{-\infty}^{t} e^{\left(-\frac{(x-n \mu)^{2}}{2 n \sigma^{2}}\right)} \mathrm{d} x .
$$

Similar with the basic model, the profit of the platform from a transaction is as follows:

$$
\pi=\alpha \operatorname{drlp}-(d+\mathrm{drl}) p p_{d}
$$

where $\alpha \mathrm{drlp}$ is the expected commission revenue of the financing platform from a transaction, and $d(1+r l) p p_{d}$ is the expected default cost from a transaction.

The platform maximizes its revenue by adjusting the commission rate $\alpha$. Then, we obtain the following proposition:

Proposition 2. With a general distribution of $x_{i}$, there is an optimal $\alpha^{*}$ which solves

$$
\operatorname{rlp}(\alpha)+\left(\alpha r l-p_{d}-\operatorname{rlp}_{d}\right) p^{\prime}(\alpha)=0 .
$$

As shown in Figure 1, the platform's revenue is maximized at the optimal commission rate $\alpha^{*}$. When the loan raising time is normally distributed, the model is too complicated such that we cannot obtain the analytical result. Next, we will use the numerical study to show the impact of the parameters on the optimal commission rate and the expected profit of the platform.

\section{Sensitivity Analysis}

In this section, we will use the numerical study to show the impact of the parameters on the optimal commission rate and the expected profit of the platform. We do a lot of numerical studies and represent a representative one. We set the parameters as follows: $l=3, k=0.5, b=60, p_{d}=0.003$, $t=10, r=[5 \%, 30 \%], n=30$.

As shown in Figure 2, when the interest rate $r$ rises, since $Y$ is normally distributed, the increment of the commission rate $\alpha^{*}$ has little influence on the decreasing of the successful transaction probability $p$ but can significantly impact on the revenue increment. Then, the platform's profit will increase.

As shown in Figure 3, when the required raising time increases, the probability of a successful transaction increases. Then, the platform will increase the commission rate $\alpha^{*}$ to increase its profit.

As shown in Figure 4, when the required investment times $n$ increase, the probability of the successful transaction will be decreased, so in order to obtain the high revenue, the platform will increase the probability of a successful transaction by decreasing the commission rate. When the investment times $n$ are low, the commission rate's decrement 


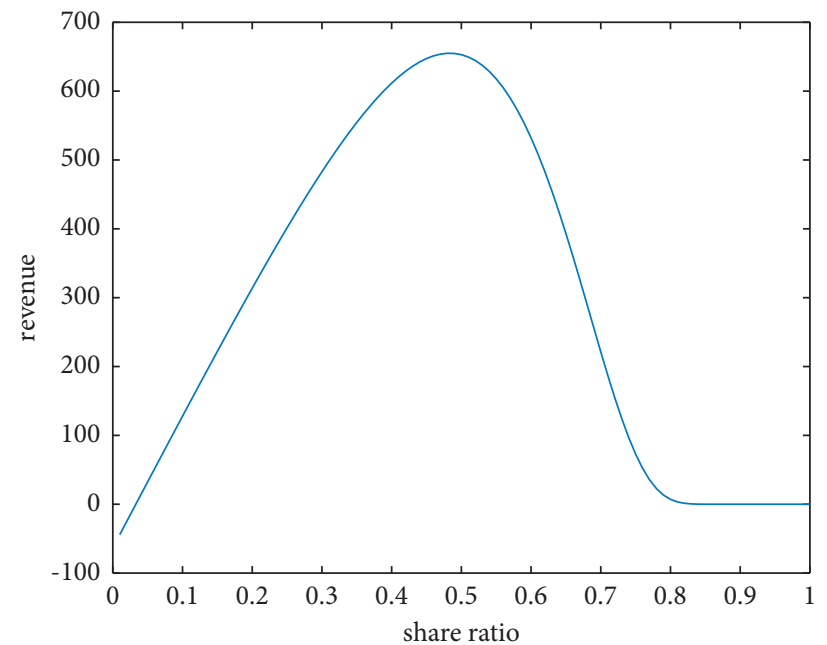

FIgURE $1: \alpha=[0,1], l=3, k=0.5, b=60, p_{d}=0.003, t=10, r=20 \%, n=20$.

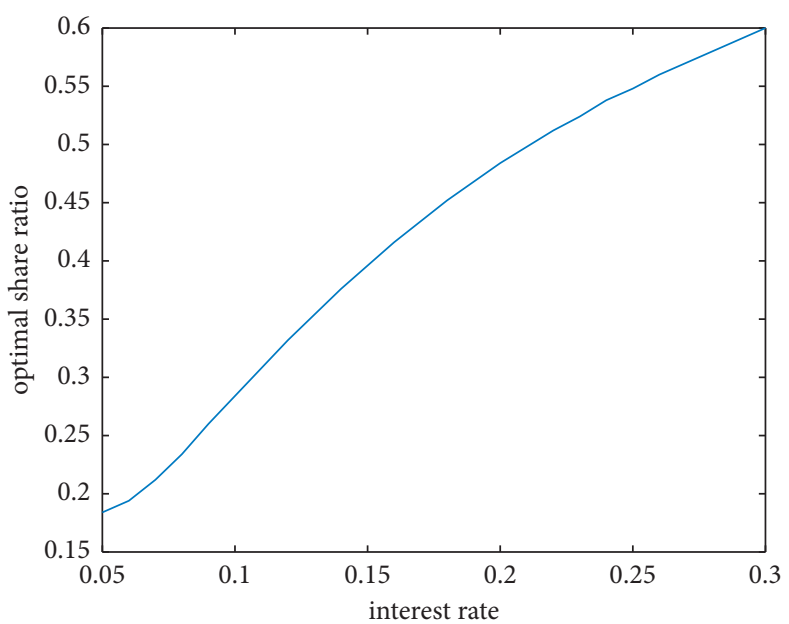

_ platform

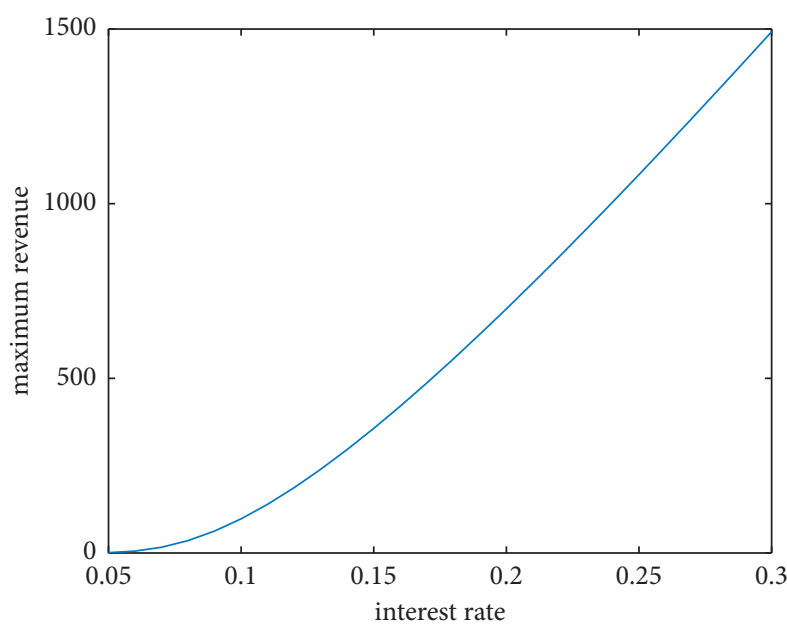

_ platform

Figure 2: The impact of interest on the optimal commission rate and the maximum profit.
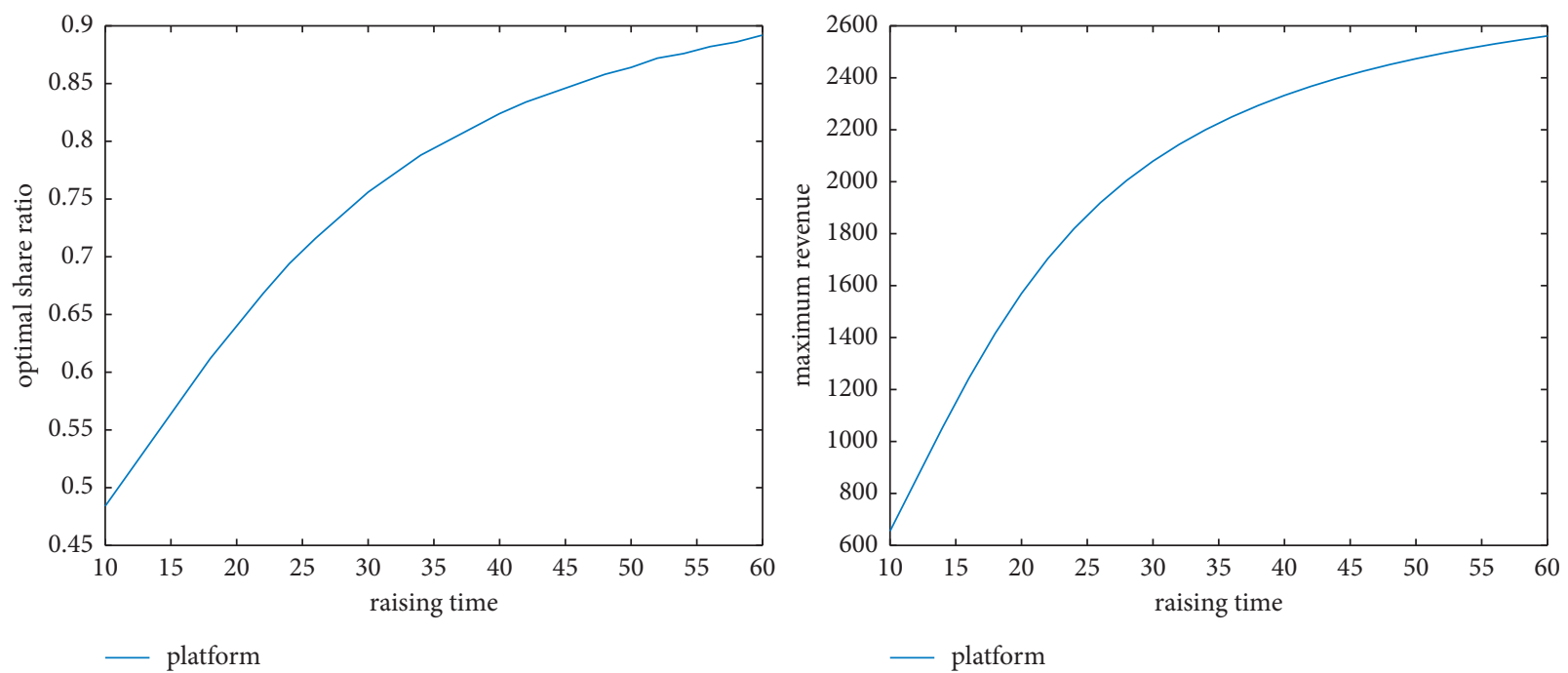

FIgURE 3: The impact of raising time on the optimal commission rate. 

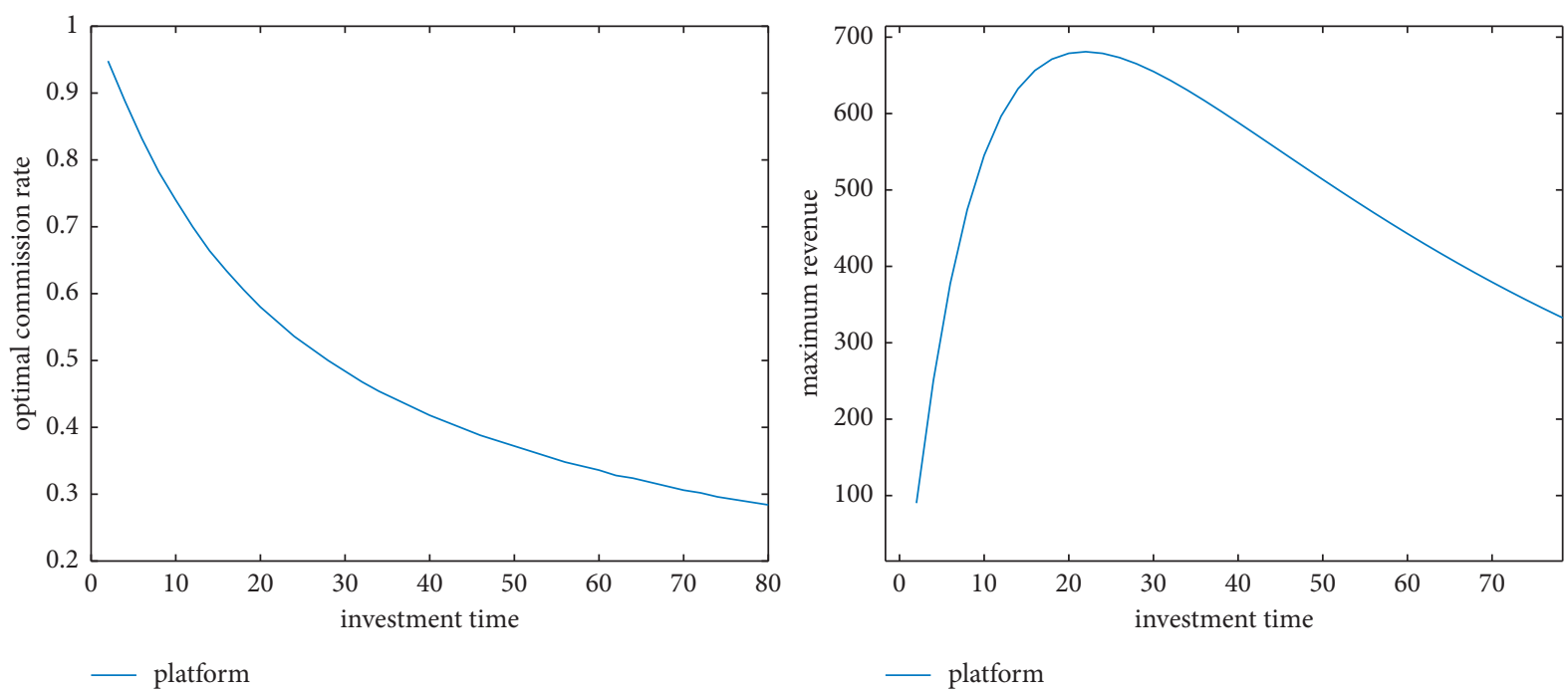

Figure 4: The impact of investment times on the optimal commission rate and maximum revenue of the platform.

increases the probability of the successful transaction, so the expected profit is increased. However, when the investment times $n$ are high, the impact of the commission rate's decrement on the probability of the successful transaction is weak, and the probability of the successful transaction decreases such that the expected profit is decreased.

As shown in Figure 5, similar to the basic model, the probability of a successful transaction is not affected by the loan duration $l$. When the loan duration $l$ increases, but the revenue of the successful transaction will be increased, so in order to obtain the high revenue, the platform will increase the probability of a successful transaction by decreasing the commission rate. In addition, the loan duration increases the platform's revenue, so the expected profit is increased.

In the next part, we continue to extend the model to the duopoly case.

\section{Duopoly Competition}

In this section, we will study the duopoly competition between the two fund-raisers in the same platform. When an investor chooses a loan project, it is inevitable to compare two projects and choose the most favorable one. This leads to competition among different fund-raisers.

In this paper, we assume that there are two identical fund-raisers $\mathrm{A}$ and $\mathrm{B}$ on the same platform, who provide interest values of $r_{A}$ and $r_{B}$ independently. Similar to the monopoly case, we can obtain a function of the probability that the fund-raiser A can raise enough money.

In two fund-raiser cases, $\mu$ may be different as follows:

$$
\mu_{A}=\frac{\exp \left(r_{A}\right)+\exp \left(r_{B}\right)+1}{b r_{A}(1-\alpha) \exp \left(r_{A}\right)}
$$

and

$$
\mu_{B}=\frac{\exp \left(r_{A}\right)+\exp \left(r_{B}\right)+1}{b r_{A}(1-\alpha) \exp \left(r_{B}\right)}
$$

Since the fund-raisers A and B are symmetrical, we can only focus on the fund-raiser A. Similar with the monopoly case, we can obtain the probability of the fund-raiser A can raise enough money.

$$
p_{A}=\frac{1}{\sqrt{2 \pi n} \alpha} \int_{-\infty}^{t} e^{\left(-\frac{\left(x-n \mu_{A}\right)^{2}}{2 n \alpha^{2}}\right)} d x .
$$

Knowing the probability $p_{A}$, we obtain the expected profit of the fund-raiser $A$, and the expected profit of the fund-raiser B is similar.

$$
\begin{aligned}
\pi_{A} & =\left(c d-d r_{A} l\right) p_{A}\left(r_{A}\right), \\
\pi_{B} & =\left(c d-d r_{B} l\right) p_{B}\left(r_{B}\right),
\end{aligned}
$$

where $c$ is the returns that the fund-raiser A or B earns by using the money borrowed from the platform. The two fundraisers compete with each other by deciding their interest rate $r_{A}$ and $r_{B}$, respectively. We obtain the following proposition:

Proposition 3. There is a Nash equilibrium in the duopoly competition between the two fund-raisers, such that $r_{A}^{*}=r_{B}^{*}$ and $\pi_{A}^{*}=\pi_{B}^{*}$.

In the duopoly case, since the fund-raisers $A$ and $B$ are homogeneous, the fund-raisers $A$ and $B$ will choose the same interest rate and finally obtain the same profit in the equilibrium. In order to compare the difference between the monopoly and duopoly cases, we use the numerical drawing to compare the two cases with each other.

As shown in Figure 6, the fund-raiser's profit $A(B)$ is concave in the interest rate $r_{A}\left(r_{B}\right)$. Then, there is an optimal interest rate for fund-raisers that can let them obtain the maximum profit. Due to lacking competition, the optimal interest rate in the monopoly case is lower than that in the duopoly case. Because the interest rate is cost for the fundraiser, the expected profit of the fund-raiser in the monopoly is higher than the expected profit of each fund-raiser in the 

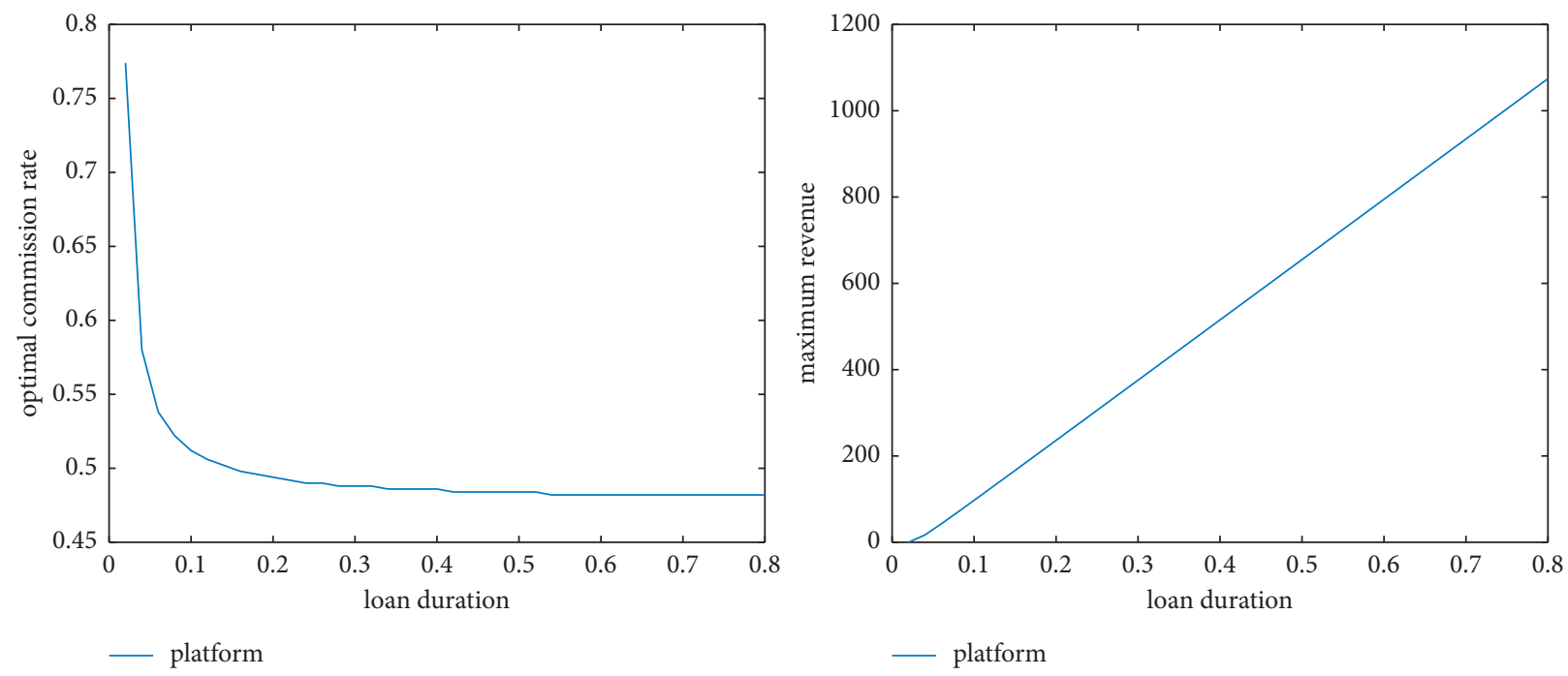

Figure 5: The impact of loan duration on the optimal commission rate and maximum revenue of the platform.

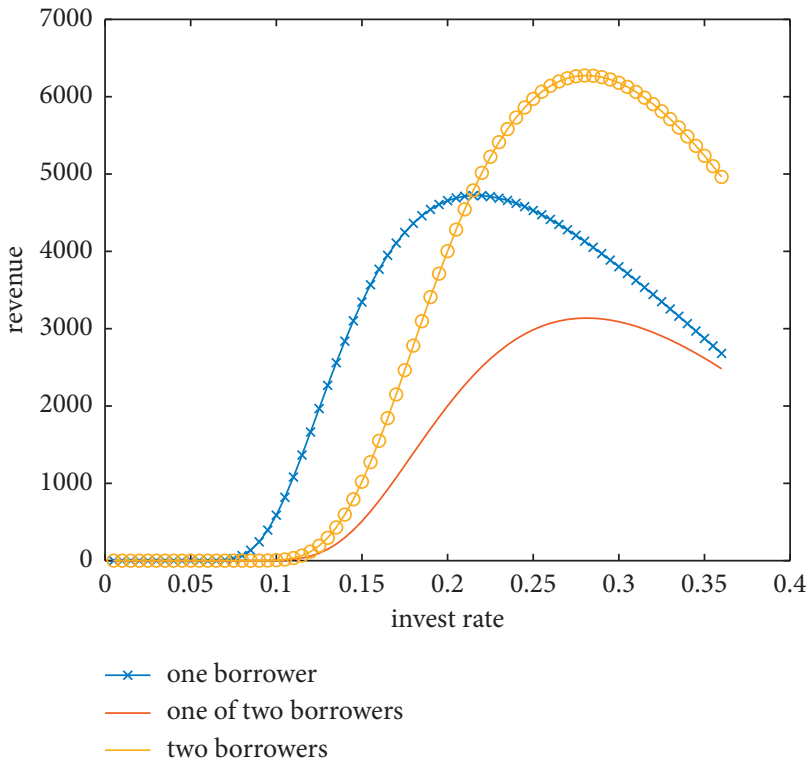

FIGURE 6: The impact of the interest rate on the platform revenue.

duopoly case but is lower than the total expected profit of the two fund-raisers.

\section{Conclusions}

We construct a stochastic model to study the fund matching between fund-raisers and investors in a financing platform. The raising time is assumed to be a random variable. Then, there is a successful transaction probability that the fund matching is realized. Meanwhile, the interest and the commission rates that the platform earns affect the value of the probability. The platform maximizes its revenue by adjusting the commission rate.

When the raising time is uniformly distributed, we find that the optimal commission rate increases in the probability of the borrower default but decreases in the annual interest rate and the loan duration. We extend the model into a more general one, in which the platform needs more than one investor to raise enough money for the borrower, and the time interval between two adjacent investments obeys the general distribution. We find that the optimal commission rate increases in the annual interest rate and raising time but decreases in the loan duration. The platform should choose some small loans as far as possible. The loans with smaller amount are easier for the platform to complete fundraising. For those large loans, the platform should try to ask for higher interest rates or more sufficient time to raise funds.

Besides, we extend the model into a duopoly case in which two fund-raisers compete for customers in the same platform by deciding their own interest rate. Due to lacking competition, the optimal interest rate in the monopoly case is lower than that in the duopoly case. Because the interest rate is cost for the fund-raiser, the expected profit of the fund-raiser in the monopoly is higher than the expected profit of each fund-raiser in the duopoly case but is lower than the total expected profit of two fund-raisers.

\section{Appendix}

Proof.

Proposition 4. Taking the first order derivative of $\pi$ with respect to $\alpha$, we obtain

$$
\pi=p(\alpha) \mathrm{drl}+p^{\prime}(\alpha) \alpha \mathrm{drl}-(d+\mathrm{drl}) p_{d} p^{\prime}(\alpha),
$$

$p^{\prime}(\alpha)=\frac{t}{\operatorname{ar}(1-\alpha)^{2}}$.

Let the result of derivation be zero, we have

$$
r l-2 \alpha r l+p_{d}+r l p_{d}=0 .
$$

We can obtain the optimal commission rate. 
Proposition 5. In order to find out the maximum revenue of the platform and the value of $\alpha$ when obtaining the maximum revenue, we can obtain the following results about the derivation of $m$ to /alpha:

$$
m^{\prime}=p(\alpha) \mathrm{drl}+p^{\prime}(\alpha) \alpha \mathrm{drl}-(d+\mathrm{drl}) p_{d} p^{\prime}(\alpha) .
$$

Because the expression of $P$ contains definite integral and the definite integral is not integrable, the integrand function is expanded by applying McLaughlin expansion as follows:

$$
p=\frac{1}{\sqrt{2 n \pi} \sigma} \int_{-\infty}^{t} \sum_{i=0}^{\infty} \frac{\left(-(x-n \mu)^{2} / 2 n \sigma^{2}\right)^{i}}{i !} \mathrm{d} x \text {. }
$$

After integration and simplification, we can obtain the following results:

$$
p=\frac{1}{\sqrt{2 n \pi} \sigma} \sum_{i=0}^{\infty} \frac{(t-n \mu)^{2 i+1}-(-w-n \mu)^{2 i+1}}{(2 i+1) i !\left(-2 n \sigma^{2}\right)^{i}} \mathrm{~d} x .
$$

As for the derivation of $P$ to -alpha, we use $-W$ to replace $-\infty$ and obtain that

$$
p^{\prime}=\frac{1}{\sqrt{2 n \pi} \sigma} \sum_{i=0}^{\infty} \frac{n(-W-n \mu(\alpha))^{2 i}-n(t-n \mu(\alpha))^{2 i}}{i !\left(-2 n \sigma^{2}\right)^{t}} \mu^{\prime}(\alpha)
$$

where

$$
\mu^{\prime}(\alpha)=\frac{1}{b r(1-\alpha)^{2}}
$$

By applying the McLaughlin expansion to the above formula, we can obtain the following results:

$$
p^{\prime}(\alpha)=(N(-W)-N(t)) \mu^{\prime}(\alpha),
$$

and

$$
N(x)=\frac{1}{\sqrt{2 n \pi} \sigma} e^{\left(-(x-n \mu)^{2} / 2 n \sigma^{2}\right)} .
$$

In order to prove the existence of extremum of $M$, we find the relation between $M$ and $m \alpha$ The second derivative can be obtained as follows:

$$
m^{\prime \prime}=2 \operatorname{drlp}^{\prime}(\alpha)+\left(\alpha \operatorname{drl}-(d+\operatorname{drl}) p_{d}\right) p^{\prime \prime}(\alpha),
$$

where

$$
\begin{aligned}
p^{\prime \prime}(\alpha)= & ((-W-n \mu) N(-W)-(t-n \mu) N(t)) \mu^{\prime}(\alpha) \\
& +(N(-W)-N(t)) \mu^{\prime \prime}(\alpha),
\end{aligned}
$$

and

$$
\mu^{\prime \prime}(\alpha)=\frac{1}{2 b r(1-\alpha)^{3}}
$$

To sum up, when $\alpha \mathrm{drl}-(d+\mathrm{drl}) p_{d}>0$ is satisfied, $m^{\prime \prime}$ is less than zero.

$$
\operatorname{drlp}(\alpha)+d\left(\alpha r l-p_{d}+\operatorname{drlp}_{d}\right) p^{\prime}(\alpha)=0,
$$

so there is an optimal $\alpha^{*}$. Let platform's revenue takes the maximum value $m^{*}$.

Proposition 6. In order to prove the existence of the best solution for the borrower, in this case, we need to prove that the sufficient conditions of the supermodel game are met. Finding the partial derivative of $\pi_{A}$ with respect to $r_{A}$ and then finding partial derivative to $r_{B}$, we obtain

$$
\frac{\partial^{2} \pi_{A}}{\partial r_{A} \partial r_{B}}=\left(c d-d r_{A} l\right) \frac{\partial^{2} p_{A}}{\partial r_{A} \partial r_{B}}-d l \frac{\partial p_{A}}{\partial r_{B}} .
$$

Using McLaughlin expansion to simplify $p$ and Finding partial derivative of $p$, we obtain

$$
\begin{aligned}
\frac{\partial p_{A}}{\partial r_{A}} & =(N(-W)-N(t)) \frac{\partial \mu_{A}}{\partial r_{A}}, \\
\frac{\partial p_{A}}{\partial r_{B}} & =(N(-W)-N(t)) \frac{\partial \mu_{A}}{\partial r_{B}}, \\
\frac{\partial^{2} p_{A}}{\partial r_{A} \partial r_{B}}= & \left(\left(-W-n \mu_{A}\right) N(t)\right) \frac{\partial \mu_{A}}{\partial r_{A}} \frac{\partial \mu_{A}}{\partial r_{B}} \\
& +(N(-W)-N(t)) \frac{\partial^{2} \mu_{A}}{\partial r_{A} \partial r_{B}},
\end{aligned}
$$

where

$$
\begin{aligned}
N(x) & =\frac{1}{\sqrt{2 n \pi} \sigma} e^{\left(-\left(x-n \mu_{A}\right)^{2} / 2 n \sigma^{2}\right)}, \\
\frac{\partial \mu_{A}}{\partial r_{A}} & =-\frac{\left(r_{A}+1\right)\left(e_{B}^{r}+1\right)+e_{A}^{r}}{b(1-\alpha) r_{A}^{2} e_{A}^{r}}, \\
\frac{\partial \mu_{A}}{\partial r_{B}} & =-\frac{e_{B}^{r}}{b(1-\alpha) r_{A} e_{A}^{r} .}
\end{aligned}
$$

When $n \mu<t$, because $c d-d r_{A} l>0, \partial^{2} p_{A} / \partial r_{A} \partial r_{B}>0$, and $\partial p_{A} / \partial r_{B} \leq 0$, so $\partial^{2} m_{A} / \partial r_{A} \partial r_{B}>0$. In this situation, $\pi_{A}$ is the sufficient conditions for the supermodel game, so there is a maximum value of $m_{A}$, and the maximum value $m_{A}^{*}$ is obtained when the optimal solution $r_{A}^{*}$ is obtained.

\section{Data Availability}

No data were used to support this study.

\section{Conflicts of Interest}

The authors declare that they have no conflicts of interest.

\section{Acknowledgments}

This research was funded by the National Natural Science Foundation, China (grant no. 71801233), and Department of Science and Technology of Guangdong Province (grant no. 2020A0505090004). 


\section{References}

[1] R. R. Suryono, I. Budi, and B. Purwandari, "Detection of fintech P2P lending issues in Indonesia," Heliyon, vol. 7, no. 4, Article ID e06782, 2021.

[2] L. Deer, J. Mi, and Y. Yuxin, "The rise of peer-to-peer lending in China: an overview and survey case study," Association of Chartered Certified Accountants, 2015.

[3] L. Cui, Y. Jiao, L. Bai, L. Rossi, and E. R. Hancock, Adaptive Feature Selection Based on the Most Informative Graph-Based Features International Workshop on Graph-Based Representations in Pattern Recognition, Springer, Cham, 2017.

[4] Z. P. Zhang and X. L. Hu, "The development of P2P: a literature review," East China Economic Management, vol. 9, pp. 159-164, 2013.

[5] S. Freedman and G. Z. Jin, "Do social networks solve information problems for peer-to-peer lending? Evidence from Prosper. com," SSRN Electronic Journal, 2008.

[6] E. Lee and B. Lee, "Herding behavior in online P2P lending: an empirical investigation," Electronic Commerce Research and Applications, vol. 11, no. 5, pp. 495-503, 2012.

[7] P. Bing, "Peer-to-peer lending and illegal financing," Financial Regulation Research, vol. 6, 2014.

[8] L. Xin and L. Huimin, "Operation mode and risk control of P2P network lending," Reformation, vol. 2, 2015.

[9] W. Zhang, C. Wang, Y. Zhang, and J. Wang, "Credit risk evaluation model with textual features from loan descriptions for P2P lending," Electronic Commerce Research and Applications, vol. 42, Article ID 100989, 2020.

[10] K. Abbasi, A. Alam, N. A. Brohi, I. Ali Brohi, and S. Nasim, "P2P lending Fintechs and SMEs access to finance," Economics Letters, vol. 204, Article ID 109890, 2021.

[11] R. Galema, "Credit rationing in P2P lending to SMEs: do lender-borrower relationships matter?" Journal of Corporate Finance, vol. 65, Article ID 101742, 2020.

[12] M. Gao, J. Yen, and M. Liu, "Determinants of defaults on P2P lending platforms in China," International Review of Economics \& Finance, vol. 72, pp. 334-348, 2021. 